Dhaka Univ. J. Biol. Sci. 27(2): 145-154, 2018 (July)

\title{
GENDER DIFFERENCES IN COPING STYLES OF PATIENTS WITH DEPRESSION: A COMPARATIVE STUDY
}

\author{
Anita Rani Saha* and Farah Deeba \\ Department of Clinical Psychology, University of Dhaka, Dhaka-1000, Bangladesh
}

Key words: Gender, Coping styles, Depression, Comparative study

\begin{abstract}
The present study was undertaken to investigate the gender differences in coping styles of patient with depression. Three types of coping styles were measured: problem focused, emotion focused and dysfunctional copings. The sample consisted of 101 participants (Male $=61,60.4 \%$ ) and (Female $=40,39.6 \%$ ) diagnosed with depression who were selected through convenience sampling technique from different hospitals of Dhaka city. Depression scale (DS), adapted Bengali version of Hospital Anxiety and Depression Scale (HADS) and adapted Bengali version of COPE scale were used to assess different variables for the present study. Results of the study indicated that male patients were tending to use more problem focused coping styles than females and female patients were tending to use more dysfunctional coping style than male. There was no gender difference found in the groups on emotion focused coping style. Based on the findings developing a better therapeutic intervention to treat depression, was discussed.
\end{abstract}

\section{Introduction}

A wide range of research has documented that women suffer from depression and stress reaction more than men ${ }^{(1,2)}$. Probably women face higher number of chronic stresses in everyday life compared to men, and these strains could contribute to their higher level of depression ${ }^{(3)}$. Gender affects each element in the stress process as much in the input, by determining whether a situation will be perceived as stressful, as in the output, influencing coping responses and the implications of stress reactions ${ }^{(4)}$. Like perceptions of stress, males and females develop and use of coping styles to adapt with everyday life. However, it is observed that, males and females differ in the coping styles on which they are likely to rely for adaptation ${ }^{(5)}$. The term "coping styles" was defined by Lazarus and Folkman(6) constantly changing cognitive and behavioral efforts to manage specific external or internal demands that are appraised as taxing or exceeding the resources of the person. Coping styles play a major role in individual's physical and psychological well-being when he or she is confronted with negative or stressful life events $^{(7-8)}$. Coping is seen to play in mediating between antecedent stressful events and outcomes such as depression, anxiety, psychological distress ${ }^{(9-10)}$. Most of the research

*Author for correspondence: <sahaa102@gmail.com>. 
findings emphasized on two coping dimensions those are problem-focused coping styles (task oriented coping) is aimed at problem solving or doing something to alter the source of stress, whereas emotion focused coping styles (personal emotion oriented coping) is aimed at reducing or managing the emotional distress. They suggest that there is a third basic style that may be used in coping with stress, namely, avoidance. Avoidance (dysfunctional coping) is aimed at more indirect efforts to adjust to the stressor by palliating feelings or avoiding the stressor, that can include either person-oriented strategies or task-oriented strategies ${ }^{(11-13)}$.

Gender differences in coping have typically been found for seeking social support: female reported higher scores than male(14-15). Earlier research work studied depressive clinical groups, where greater help-seeking behaviors and self-disclosure by women were thought to be possible explanatory factors to the female preponderance ${ }^{(16,17)}$.

In the aspect of emotion focused coping seeking emotional social support is getting moral support, sympathy or understanding. This style is used more as outlets for the ventilation of one's feeling. Research evidence suggests that this way may not be always very adaptive ${ }^{(18-19)}$. Another emotion-focused coping style is positive reinterpretation and growth. This style aimed at managing distress emotions rather than dealing with the stressor essentially(20). Acceptance is another emotion focused coping opposite to denial. It is controversial that acceptance is a functional coping style; a person who accepts the reality of a stressful situation would seem to be a person who is engaged in the attempt to deal with the problem and turning to religion is another important emotion-focused coping style. Research finding suggests that such coping style is quite important to many people ${ }^{(21)}$. Research demonstrated that coping methods have moderate relationship between depression and stressful events ${ }^{(22-23)}$. Generally people who use approach or problem focused coping and less on avoidant or dysfunctional coping tend to adapt better to stressor and experience better psychological outcomes such as, reduced depressive symptom ${ }^{[24]}$. Most studies that have examined coping and mental health outcomes revealed that those who used "approach" or "problem" solving techniques (problem-focused coping) to manage stress were at lower risk for depression than those who used emotion- or avoidance-focused coping techniques ${ }^{(25)}$. Research studies revealed that problem-focused coping was associated with lower depression only when the situation was appraised as changeable ${ }^{(26)}$. Other findings suggested that, depression influenced the choice of coping styles; thus, people who were depressed more likely adopt avoidance or dysfunctional coping strategies than those who are not depressed (27). Contemporary coping studies suggested that, women were more likely to use emotionfocused coping styles compared to men ${ }^{(28-29)}$. The greater depressiveness of women might be due partly to their less effective coping styles ${ }^{(30)}$. In Bangladesh the life time prevalence rate of major depressive disorder is $4.6 \%$.Among the Bangladeshi population $4.6 \%$ are found to be suffering from depression making it one of the most prevalent mental health problems in Bangladesh ${ }^{(29-31)}$. 
Studies have consistently recognized that coping styles has an influential impact on depression determining gender differences. So it is necessary to conduct study on this important topic in the context of our society. The present study, therefore, aims to investigate gender differences in coping styles of patients with depression.

\section{Materials and Methods}

The sample of the present study consisted of 101 patients with depression. Among them 61 were male and 40 were female patients within the age range of 16 to 65 . They were selected by using convenience sampling technique from the out-patient and inpatient departments of Psychiatry of Dhaka Medical College and Hospital (DMCH) and, general out-patient department of National Institute of Mental Health (NIMH), Lab Aid Hospital (private practice), and Nasirullah Psychotherapy Unit, University of Dhaka. Among them 81 participants were from unban and 20 were from rural area of different districts of Bangladesh. Fifty three of the participants were married and 47 were unmarried, as well as 1 participant was separated. Among them 1 participant was illiterate, 8 were under S.S.C. 17 were S.S.C. to H.S.C., 72 were Honors to Masters, other 3 were from medical background. Their occupations were students, job, business, unemployed, and housewife, with the monthly income of 41 participants were under Tk. 20000, 50 were Tk. 20000 to Tk. 70000 and 10 were above Tk. 70000. All the participants were diagnosed with depression by the psychiatrist following (DSM-5) diagnostic criteria, among them 90 were depressive patients without other physical conditions and 11 were depressive patients with other physical conditions (Diabetes, hypothyroidism). Among them 90 were newly diagnosed and 11 were relapse case of depression. We excluded the patients who had secondary depression with other mental conditions. The demographic variables of participants are presented in Table 1.

The following three scales were used for collecting relevant data. Among them two were depression scales and the other was cope scale. We used two depression scales for measuring depression but depressed patients might have some symptoms of anxiety and the HADS scale measured both depression and anxiety. The measures are described as follows.

The hospital anxiety and depression scale (Zigmond and Snaith 1983) is a wellknown and widely used self-report measures of depression (seven items) and anxiety (seven items) as two distinct dimensions, on a 4 -point $(0=$ no distress to $3=$ significant distress) response scale. Each item is scored from 0 to 3 and the total score range from 0 to 21 for depression as well as for anxiety sub-scale. Two factor model proposed by Zigmond and Snaith satisfactory levels of Cronbach's alphas were found for anxiety and depression factors in the community $(\alpha=0.83$ and 70) and clinical $(\alpha=0.86$ and 0.76) samples ${ }^{(32)}$. Expanding research on HADS's validity by reviewing 747 identified papers, there was found correlations between Beck's Depression Inventory (BDI) and HADS. The 
correlation between BDI and HADS-D were (0.62 to .73), BDI and HADS-A (0.61 to 0.83 ) and BDI and HADS-total score (HADS-T $=.73$ ) and this indicates good concurrent validity of the HADS. Similar findings of internal consistency from different translations of HADS supported the robustness of the instrument ${ }^{[33]}$. According to Zigmond and Snaith, scores from 11 to 21 is used to indicate probable psychiatric disorder. So a cut off score of 11 and above is recommended for identifying probable psychiatric diagnosis ${ }^{(34)}$. The Bengali version of the $\operatorname{HADS}^{(35)}$ was used for the present study. The correlation coefficient between the original and translated version of the HADS sub-scales for anxiety was 0.76 and depression sub-scale was 0.94. Examination of the Cronbach alpha coefficient in the present study was $(\alpha=0.70)$ illustrated that an acceptable level of internal consistency was observed for this measure.

Table 1. Demographic data of variables according to male and female.

\begin{tabular}{lllll}
\hline & & Total & Male & Female \\
& & $\mathrm{N}=101,100 \%$ & $\mathrm{~N}=61,60.4 \%$ & $\mathrm{~N}=40,39.6 \%$ \\
\hline Age & Mean & 30.58 & 29.33 & 32.50 \\
& Sd & 9.41 & 7.81 & 11.26 \\
$(\mathrm{~N}, \%)$ & Unmarried & 53 & 40 & 13 \\
& & $52.5 \%$ & $65.6 \%$ & $32.5 \%$ \\
& Married & 47 & 20 & 27 \\
& & $46.5 \%$ & $32.8 \%$ & $67.5 \%$ \\
Types of patents & Separated & 1 & 1 & 0 \\
$(\mathrm{~N}, \%)$ & & $1.0 \%$ & $1.6 \%$ & \\
& New case & 90 & 53 & 37 \\
& & $89.1 \%$ & $86.9 \%$ & $92.5 \%$ \\
Types of depression & Relapse case & 11 & 8 & 3 \\
$(\mathrm{~N}, \%)$ & & $10.9 \%$ & $13.8 \%$ & $7.5 \%$ \\
& Depression without any & 90 & 57 & 33 \\
& physical condition & $89.1 \%$ & $93.4 \%$ & $82.5 \%$ \\
& Depression with other & 11 & 4 & 7 \\
& physical condition & $10.9 \%$ & $6.6 \%$ & $17.5 \%$ \\
\hline
\end{tabular}

Depression scale (Uddin and Rahman 2005) is a five point rating scale consisted of 30 positive items with five alternative answers indicating five points, ranges from 'not at all applicable' for score 1, 'not applicable' for score 2, 'uncertain' for score 3, 'a bit applicable' for score 4, and totally applicable for score 5. Sum of all values (for 30 items) indicated the total score and severity of depression. Highest score on the scale was 150 and lowest was 30. Score ranges for minimal, mild, moderate and severe were $30-100$, 101 - 114, 115 - 123, and 124 - 150 accordingly. The cut-off point on the scale which can 
differentiate between clinically depressed and non-depressed individuals was 94 . Individual obtaining score of 94 or more was considered as clinically depressed. Both the split half reliability (Guttman split- half $r=0.7608, p<0.01$ and the test-retest reliability $(r=0.599, p<0.01)$ for the scale ensured it as a reliable measure. Concurrent validity of the scale was also estimated by the rating scale. Rating of depression by the psychiatrist $(\mathrm{r}=0.377, \mathrm{p}<0.01)$ and self-rating by the patients $(r=0.558, \mathrm{p}<0.01)$ were positively correlated with the obtained scores on the depression scale. Discriminability ( $F=85.386$, $\mathrm{p}<0.01)$ of the depression scale also indicated its satisfactory concurrent validity ${ }^{(36)}$. Construct validity of the current scale was estimated by computing correlation between current depression scale and depression sub scale of translated version of Hospital Anxiety and Depression scale. It was found that two scales were positively correlated $(\mathrm{r}=$ $0.716, \mathrm{p}<0.01)$ and examination of the Cronbach alpha coefficient in the present study was $(\alpha=0.87)$ illustrated that an acceptable level of internal consistency was observed for this measure(36).

COPE scale: (Carver et al. 1989)(12) is used to assess coping strategies. The COPE scale is a theoretically based 60 items self-report measure. Participants were instructed to report what they usually do under stress. Respondents choose their answers based on a four-point scale that is anchored at 'not at all' for score (1), to 'a lot of' for score (4). The scale measured three types of scores: Problem-focused, emotion-focused, and dysfunctional coping with five scale per group and four items per scale, (a) problem focused coping: active coping, planning, suppression of competing activities, restraint coping, and instrumental social support, (b) emotion focused coping: emotional social support, positive reinterpretation and growth, acceptance, turning to religion, and humor, (c) dysfunctional coping: venting of emotions, denial, behavioral disengagement, mental disengagement, and alcohol or drug use. The scores were determined by summing the items under each group. The scale had alpha reliabilities all above 0.6 except for the mental disengagement scale 0.45 and with a few exceptions the internal validity of the individual COPE scale do not have excessive inter-correlation ${ }^{(12)}$. The Bengali version of COPE was used to assess coping styles of the participants( ${ }^{(37)}$. The correlation between English and Bengali version was found to be 0.87, and the test-retest reliability was found to be 0.85 and examination of the Cronbach alpha coefficient in the present study was $(\alpha=0.84)$ illustrated that an acceptable level of internal consistency was observed for this measure, the convergent validity of the Bengali version was determined by computing correlations among the subscales of $\mathrm{COPE}^{(37)}$.

First of all permission was gathered from the concerned authority of hospitals where there were psychiatric or psychotherapy department, for collecting data. Data collected were done only from the hospitals that provided permission. At the beginning each of the participants was approached individually. Consent of the participants was taken and necessary rapport was established before administering the questionnaire. The 
participants were asked to read the instructions before filling the items of the scales. The questionnaires were read out to the respondents with low educational background. The participants were informed about confidentiality of data and use for research purpose only. The participants were also informed that they were free to withdraw if he or she does not want to continue answering. After completing the procedure a copy of consent paper was given to each participant.

\section{Results and Discussion}

Gender differences in coping styles were studied in a sample of patients with depression. The present study was carried out to determine whether coping styles varies in terms of gender or not. In order to find out the difference between male and female regarding coping styles t-test was applied on those data. It was found that the mean score of problem focused coping style was significantly higher among male than among female. On the other hand women scored significantly higher in dysfunctional coping style than male. Comparison of the emotion focused coping style of male and female showed that there was no difference between these two groups. Correlations among the variables in the present study are given in Table 2.

Table 2. Correlation between gender and outcome measures.

\begin{tabular}{|c|c|c|c|c|c|c|c|}
\hline & 1 & 2 & 3 & 4 & 5 & 6 & 7 \\
\hline Gender & & 0.02 & $0.34^{* *}$ & -0.01 & -0.31 & $0.04^{* *}$ & $0.21^{*}$ \\
\hline Depression scale & & & $0.36^{* *}$ & $0.65^{* *}$ & $0.35^{* *}$ & 0.18 & $0.31^{* *}$ \\
\hline Hospital anxiety & & & & $0.24^{*}$ & 0.08 & 0.10 & $0.25^{*}$ \\
\hline Hospital depression & & & & & $0.37^{* *}$ & -0.02 & 0.08 \\
\hline Problem focused coping & & & & & & $0.33^{* *}$ & 0.08 \\
\hline Emotion focused coping & & & & & & & $0.56^{* *}$ \\
\hline Dysfunctional coping & & & & & & & \\
\hline
\end{tabular}

All tests are two tailed. $\mathrm{N}=101,{ }^{* *} \mathrm{p}<0.01,{ }^{*} \mathrm{p}<0.05$.

To see difference in problem-focused, emotional focused and dysfunctional coping strategies independent $t$-tests were run in SPSS 19. Results are given in Tables 3-5.

Result of the present study was consistent with the formulated objectives and previous research findings ${ }^{(38)}$. Coping is a very important factor for patients with depression. Research work documented that, men and women reported differences in the coping styles they employ, with women reporting greater endorsement of an avoidant or dysfunctional coping style, and men reporting greater endorsement of an action or problem focused coping style ${ }^{(5)}$. Women are also prompt to make more frequent 
use of emotional discharge or venting of emotion that is basically dysfunctional ways of coping. Research findings reveal that gender distinctions encourage females to avoid directly confronting problems, but to engage in emotional attentiveness or rumination, contributing to depressive symptoms ${ }^{(18)}$. It was further found that people who are depressed more likely use or adopt avoidance or dysfunctional coping strategies than those who are not depressed ${ }^{(39)}$. Women on average cope less effectively with adversities than men and that lead them to be depressed ${ }^{(40)}$.

Table 3. The difference in problem focused coping between male and female patients with depression.

\begin{tabular}{lccccc}
\hline Group & $\mathrm{M}$ & $\mathrm{Sd}$ & $\mathrm{t}$ & $\mathrm{df}$ & Exact $\mathrm{p}$ value \\
\hline Male & 2.97 & 0.55 & 3.26 & 99 & $0.002^{* *}$ \\
Female & 2.63 & 0.44 & & & \\
\hline
\end{tabular}

${ }^{* *} \mathrm{p}<0.01$.

Table 4. The difference in emotion focused coping between male and female patients with depression.

\begin{tabular}{lllclc}
\hline Group & $\mathrm{M}$ & $\mathrm{Sd}$ & $\mathrm{t}$ & $\mathrm{df}$ & Exact $\mathrm{p}$ value \\
\hline Male & 2.50 & 0.31 & -0.41 & 99 & 0.685 \\
Female & 2.53 & 0.33 & & & \\
\hline
\end{tabular}

$\mathrm{p}>0.05$.

Table 5. The difference in dysfunctional coping between male and female patients with depression.

\begin{tabular}{llrcrc}
\hline Group & $\mathrm{M}$ & $\mathrm{Sd}$ & $\mathrm{t}$ & $\mathrm{df}$ & Exact $\mathrm{p}$ value \\
\hline Male & 2.23 & 0.42 & -2.15 & 99 & $0.034^{*}$ \\
Female & 2.40 & 0.37 & & & \\
\hline
\end{tabular}

* $\mathrm{p}<0.05$.

The present study gave us a new dimension to understand how much gender varies in coping styles when they are in depression. Male and female patients with depression usually adopt different coping styles to cope with depression. This study would be helpful for understanding whether these coping styles are functional or dysfunctional to cope with depression and which gender is more endorsed with problem or emotion, or dysfunctional coping styles. This study will also give the outline that how they take initiative to come out depression. If the patient could understand about the problem focused coping, of emotion focused coping and dysfunctional coping styles then they 
would be able to understand that, dysfunctional coping does not serve any benefit to them. The patients will be able to infer that what resources they should use to cope better with depression. This study will create awareness among general people, psychiatrists, psychologists, clinical psychologists, counseling psychologists, mental health professionals, nurses and to people related to healthcare delivery system regarding psychiatric aspects of depression.

This study cautions generalization. It has some limitations. First of all it was limited to only hospitals of Dhaka city. Sample size was small. So we recommend further research on larger samples with better methodological sophistication. Patients with depression alone with other physical conditions likely to have diabetes and hypothyroidism and they were also included in our study. It would be better if future studies can exclude these patients. However, as an initial work as our study showed that coping styles were found to have strong impact on patients with depression, hence further research are needed to explore vulnerability of depression and impact of coping styles in the lives of the clients and how to come out of depression and ensurerelapse prevention, this psychological component is very important.

\section{References}

1. Piccinelli M 2000. Gender differences in depression: Critical review. The British Journal of Psychiatry 177(6): 486-492.

2. Nolen-Hoeksema S 2001. Gender Differences in Depression. Current Directions in Psychological Science 10(5): 173-176.

3. Morrow J andS Nolen-Hoeksema 1990. Effects of responses to depression on the remediation of depressive affect. Journal of Personality and Social Psychology 58(3): 519-527.

4. Barnett RC, L Biener, and GK Baruch 1987. Gender \& stress. New York: The Free Press.

5. Roy-Byrne PP 2000. Dr. Roy-Byrne Replies. The Journal of Clinical Psychiatry 61(8): 602.

6. Lazarus RS and S Folkman 1984. Stress, appraisal, and coping. New York: Springer.

7. Folkman S and RS Lazarus 1986. Stress processes and depressive symptomatology. Journal of Abnormal Psychology 95(2): 107-113.

8. Endler, NS 1988. Hassles, health and happiness, In M. P. Janisse (Ed), Individual differences, stress and health psychology, New York: Springer Publishing. pp. 24-56.

9. Lay CH, JM Edwards, JD Parker and NS Endler, 1989. An assessment of appraisal, anxiety, coping, and procrastination during an examination period. European Journal of Personality 3(3): 195-208.

10. Billings AG and RH Moos 1984. Coping, stress, and social resources among adults with unipolar depression. Journal of Personality and Social Psychology 46(4): 877-891.

11. Coyne JC, C Aldwin, and RS Lazarus 1981. Depression and coping in stressful episodes. Journal of Abnormal Psychology 90(5): 439-447.

12. Carver CS, MF Scheier and JK Weintraub 1989. COPE Inventory. PsycTESTS Dataset. 
13. Eschenbeck H, C Kohlmann and ALohaus 2007. Gender Differences in Coping Strategies in Children and Adolescents. Journal of Individual Differences 28(1): 18-26.

14. Ebata AT and RH Moos 1994. Personal, Situational, and Contextual Correlates of Coping in Adolescence. Journal of Research on Adolescence 4(1): 99-125.

15. Hampel P and F Petermann 2005. Age and Gender Effects on Coping in Children and Adolescents. Journal of Youth and Adolescence 34(2): 73-83.

16. Weissman MM 1977. Sex Differences and the Epidemiology of Depression. Archives of General Psychiatry 34(1): 98.

17. Nolen-Hoeksema S 1987. Sex differences in unipolar depression: Evidence and theory. Psychological Bulletin 101(2): 259-282

18. Seiffge-Krenke I and S Shulman 1990. Coping Style in Adolescence: A Cross-Cultural Study. Journal of Cross-Cultural Psychology 21(3): 351-377.

19. Stark LJ, A Spirito, CA Williams and DC Guevremont 1989. Common problems and coping strategies reported in childhood and early adolescence. Journal of Youth and Adolescence 20: 531-544.

20. Thoits PA 1995. Social Psychology: The Interplay between Sociology and Psychology. Social Forces 73(4): 1231.

21. McCrea RR and PTJr Costa 1986. Personality, coping, and coping effectiveness in an adult sample. Journal of Personality 54: 385-405.

22. Billings AG, RC Cronkite and RH Moos 1983. Social-environmental factors in unipolar depression: Comparisons of depressed patients and non-depressed controls. Journal of Abnormal Psychology 92(2): 119-133.

23. Holahan CJ and RH Moos 1991. Life stressors, personal and social resources, and depression: A 4-year structural model. Journal of Abnormal Psychology 100(1): 31-38.

24. Endler, NS and JDA Parker 1990. Multidimensional assessment of coping: A critical evaluation. Journal of Personality and Social Psychology 58: 844-854.

25. Aranda MP, I Castaneda, P Lee and E Sobel 2001. Stress, social support, and coping as predictors of depressive symptoms: Gender differences among Mexican Americans. Social Work Research 25(1): 37-48.

26. Vitaliano PP, DJ Dewolfe, RD Maiuro, J Russo and W Katon 1990. Appraised changeability of a stressor as a modifier of the relationship between coping and depression. A test of the hypothesis of fit. Journal of Personality and Social Psychology 59: 582-593.

27. Zeidner, Moshe, S Norman and Endler 1996. Handbook of coping: Theory, research, applications, John Wiley \& Sons, Vol: 195.

28. Ptacek JT, RE Smith and J Zanas 1992. Gender, Appraisal, and Coping: A Longitudinal Analysis. Journal of Personality 60: 747-770.

29. Mohit M, M Maruf, H Ahmed and M Alam 2012. Depression and Physical Illnesses: an Update. Bangladesh Medical Journal 40(1)

30. Hänninen V and H Aro H 1996. Sex differences in coping and depression among young adults. Social Science \& Medicine 43(10): 1453-1460.

31. Chowdhury R, M Guitart-Masip, C Lambert, P Dayan, Q Huys, Düzel and RJ Dolan, 2014. Corrigendum: Dopamine restores reward prediction errors in old age. Nature Neuroscience 17(12): 1840-1840. 
32. Fong TCT and Ho RTH 2013. Factor analysis of the Hospital Anxiety and Depression Scale: a Bayesian equation modeling approach, Springer Science+ Business Media Dordecht.

33. Chowdhury KUA 2001. Emotional reaction to stress- A pilot study in Dhaka City, M. Phil. Dissertation, Unpublished.

34. Zigmond AS and RP Snaith 1983. The Hospital anxiety and Depression Scale. Acta Psychiatrica Scandinavia 67(6): 361-370.

35. Bjelland et al 2002. The validity of the Hospital Anxiety and Depression Scale An update literature review, Journal of Psychosomatic Research 52: 69-77.

36. Uddin MZ and MM Rahman 2005. Development of a scale of Depression for use in Bangladesh, Bangladesh Psychological Studies Vol. 15: 25-44.

37. Rahman A and S Islam 2011. Adaptation of the COPE Inventory for use in Bangladesh. Bangladesh Psychological Studies 21: 45-56.

38. Vingerhoets AJ and GL Heck 1990. Gender, coping and psychosomatic symptoms. Psychological Medicine 20(01): 125.

39. Zeidner, Moshe, S Norman and Endler 1996. Handbook of coping: Theory, research, applications, John Wiley \& Sons, Vol. 195.

40. Zeidner, Moshe, S Norman and Endler 1996. Handbook of coping: Theory, research, applications, John Wiley \& Sons, Vol. 195.

(Manuscript received on 10 July, 2017; revised on 18 July, 2018) 